\title{
Human Papillomavirus: Flow Cytometry Detection and PCR Analysis, A Comparison Study
}

\author{
Vasiliki E Kalodimou ${ }^{1 *}$, Marina Kontogiorgi ${ }^{3}$, Abraham Ghiatas ${ }^{2}$ and Apostolos Papalois ${ }^{3}$
}

${ }^{1}$ Department of Flow Cytometry-Research and Regenerative Medicine- "IASO"- Maternal Hospital / MedStem Services, Athens, Greece 'Department of Medical Imaging - "IASO" - Maternal Hospital / MedStem Services Athens, Greece

${ }^{3}$ Experimental - Research Center, ELPEN Pharmaceuticals, Athens, Greece

\begin{abstract}
Recent reports have shown that during persistent HPV infections of the cervical epithelium the viral genome, of high risk HPV types, often integrate into the host chromosome, which results in an over expression of the viral proteins E6 and E7 of human papillomavirus. These oncoproteins induce immortalization and malignant transformation of cells conferring a certain growth advantage to the infected cells.

A total of 100 women undergoing routine cervical cytology samples joined this cohort study. A Thin Prep Pap Test sample was taken following consent for study participation and was tested for HPV. Cytological screening of the samples was done by trained cytologists. After sample collection, $1 \mathrm{ml}$ aliquot was removed and prepared for flow cytometric analysis and the rest of the sample was sent for PCR analysis. In the total of 100 cases, 4 specimens were characterized as unsatisfactory.

For the rest 96 specimens, 82 specimens were found to be positive, for the HPV virus and 14 negative. In the total of 100 cases the analysis of flow cytometry and PCR detection gives the same results in most cases. As a conclusion, our results showed that the use of flow cytometry in the detection of HPV virus is a feasible method and requires only $1 \mathrm{ml}$ of sample specimen to give accurate results for the diagnosis.
\end{abstract}

Keywords: Human papillomavirus; PCR; Flow cytometry; Cervical cancer; E6 and E7 proteins

\section{Introduction}

Human Papillomavirus (HPV) infection is very common. It is estimated as the most common sexually transmitted disease, (high risk human papillomavirus are the necessary causes of cervical cancer) [1]. More than 100 types of HPV have been identified which can be classified as high-risk or low-risk depending on their known oncogenic activity. The vast majority of cervical cancers infections with HPV takes place in cervical epithelium and is usually of transient nature. Fortunately about $90 \%$ of HPV infections clear within two years without treatment. Only in a small amount of the women infected with oncogenic types of HPV, the infection will progress to high-grade lesions or even cervical cancer in the absence of treatment [2,3].

During persistent infections the viral genomes often integrate into the host chromosome, which results in an over expression of the viral proteins E6 and E7. These oncoproteins induce immortalization and malignant transformation of cells conferring a certain growth advantage to the infected cells [4-6]. In women 30 years and older, the current HPV testing test can be used for adjunctive screening with Pap smear to detect oncogenic types of HPV in cervical cytology specimens. Most HPV DNA assays such as type-specific polymerase chain reaction (PCR) and Hybrid Capture II (Digene) detect the present of HPV infection despite the fact that only a small proportion of the women infected with a high-oncogenic-risk type will suffer disease that progresses to cancer. Although HPV assays have a high sensitivity, their specificity is low because they detect an infection that in the vast majority of women do not develop cancer and regress spontaneously [7-9].

The detection of E6/E7 mRNA is a new approach in HPV infection monitoring $[10,11]$. The incorporation of HPV in human genome leads to E6 and E7 HPV protein production. E6 and E7 block the Rb and P53 proteins and this is the first signal in cell transforming cascade, with final result the cervical cancer. The aim of this study was to compare the PCR analysis in the detection of human papillomavirus with the detection of the virus by flow cytometry, a new technique.

\section{Materials and Methods}

A total of 100 women undergoing routine cervical cytology samples joined this cohort study. A Thin Prep Pap Test sample was taken following consent for study participation and was tested for HPV. Cytological screening of the samples was done by trained cytologists. After sample collection, $1 \mathrm{ml}$ aliquot out of $20 \mathrm{ml}$ was removed and prepared for flow cytometric analysis and the rest of the sample, (19 $\mathrm{ml}$ ), was sent for PCR analysis. The $1 \mathrm{ml}$ sample aliquot of the specimen was centrifuged at $1,000 \mathrm{~g}$ for $5 \mathrm{~min}$ at room temperature. The cell pellet was resuspended in $1 \mathrm{ml}$ phosphate buffer saline (PBS) and centrifuged at $1,000 \mathrm{~g}$ for 5 more min. Cells, then, was fixed for $1 \mathrm{~h}$ at room temperature with $300 \mu$ of Cell Perm (Invirion Diagnostics, USA - AG002). A $1 \mathrm{ml}$ of pre-hybridization buffer 1(Invirion Diagnostics, USA - AG002), was added and centrifuged at 1,000 $\mathrm{g}$ for 5 more min. Then the cell pellet was re-suspended in $1 \mathrm{ml}$ of pre-hybridization buffer 2 (Invirion Diagnostics, USA - AG002). The supernatant was re-suspending in $100 \mu \mathrm{l}$ of hybridization buffer and HPV probe cocktail

\footnotetext{
*Corresponding author: Vasiliki E Kalodimou, Lab Supervisor of Flow Cytometry - Research and Regenerative Medicine Department, IASO-Maternity Hospital, MedStem Services-Cryobanks International, Kifisias Ave.37-39, 151 25, Marousi-Athens-GR, Tel: 0030210 6185203, Fax: 0030210 6105711; E-mail: iasoflowcytometry@cryobanks.gr

Received June 05, 2015; Accepted September 23, 2015; Published September 30, 2015

Citation: Kalodimou VE, Kontogiorgi M, Ghiatas A, Papalois A (2015) Human Papillomavirus: Flow Cytometry Detection and PCR Analysis, A Comparison Study. J Clin Med Genom 3: 128. doi: 10.4172/2472-128X.1000128

Copyright: (C 2015 Kalodimou VE, et al. This is an open-access article distributed under the terms of the Creative Commons Attribution License, which permits unrestricted use, distribution, and reproduction in any medium, provided the original author and source are credited.
} 
(Invirion Diagnostics, USA - AG002), and live for $45 \mathrm{~min}$ inside the water bath at $43^{\circ} \mathrm{C}$. After the $45 \mathrm{~min}$ had pass $1 \mathrm{ml}$ of stringency wash 1(Invirion Diagnostics, USA - AG002), was added and centrifuged at $1,000 \mathrm{~g}$ for 5 more min. Then, the cell pellet was re-suspended in $1 \mathrm{ml}$ of stringency wash 2 (Invirion Diagnostics, USA - AG002), and live for another $15 \mathrm{~min}$ inside the water bath at $43^{\circ} \mathrm{C}$. At the end of the procedure the cells were centrifuged at $1,000 \mathrm{~g}$ for 5 more min, resuspended in $400 \mu \mathrm{l}$ of PBS and the samples were run on a Beckman Coulter FC500 with a $488 \mathrm{~nm}$ argon laser, with forward (FS) and side (SS) scatter. Using forward and side scatter in the flow cytometry we distinct the cervical cell populations for both the negative and positive samples by established gating. For all samples each population was determined as well as the percentage of the cells. All samples in the study were analyzed using previously established gates for the presence of endocervical, ectocervical and polymorphonuclear cells. The total time of analysis depended on the density of each specimen. The total time of sample analysis by flow cytometry was depended on the quality of the samples. The forward scatter versus side scatters dot plot was used for the distinction of ectocervical, endocervical, and polymorphonuclear cells. The gating was fixed for all samples. The instrument was set to measure absolute counts collected from the whole volume of the samples under investigation. Each population was determined and the percentage of cells included was counted.

\section{Statistical Analysis}

Data was expressed as mean $+/$-SD. Significant differences were determined by using Epi Info ${ }^{\mathrm{Tw}}$, Version 3.5.1. Results were considered significant when $\mathrm{P}<0.05$.

\section{Results}

In the total of 100 cases, 4 specimens were characterized as unsatisfactory from technical reasons, for the rest 96 specimens, 82 specimens were found to be positive for the HPV virus and 14 negative. The cervical cells found in the liquid specimen are resolved in distinct populations using forward and side scatter of a flow cytometer [10]. All the specimens in our stuffy were analyzed using previously established gates for the presence of endocervical, ectocervical and polymorphonuclear cells [10]. The instrument was set to measure absolute counts collected from the whole volume of the samples under investigation. Each population was determined and the percentage of cells included was counted.

In the total of 96 cases the analysis of flow cytometry and PCR detection gives the same results in most cases (Tables 1 and 2).

\section{A cytological diagnosis is showing in Table 3.}

The result is expressed on percentage of analyzed ectocervical cells that over express oncoproteins E6 and E7. If this percentage is over 2\% the HPV OncoTect result is positive, if it is lower it is a negative result. A negative result means there is no over expression of high-risk HPV oncoproteins E6/E7 [10]. With a negative result the risk to develop a cervical cancer in the future is almost null. A positive result means that the viral DNA has been integrated into the cell genome which results in an over expression of E6/E7 proteins.

\begin{tabular}{|l|c|c|c|c|c|}
\hline & $\begin{array}{c}\text { Hpv Oncotect } \\
\text { Results }\end{array}$ & Test Pap & Pcr High Risk & Pcr Inter. & Pcr Low \\
\hline Negative & 19 & 15 & 0 & 0 & 1 \\
\hline Positive & 81 & 85 & 62 & 14 & 9 \\
\hline
\end{tabular}

Table 1: Comparison between HPV-Oncotect and PAP test.

\begin{tabular}{|l|c|c|}
\hline & HPV Oncotect & PCR High - Inter. \\
\hline Positive & $95,30 \%$ & $89,40 \%$ \\
\hline Negative & $4,70 \%$ & $10,60 \%$ \\
\hline Positive & TEST PAP & PCR High - Inter. \\
\hline Negative & $22,00 \%$ & $0,00 \%$ \\
\hline & $78,00 \%$ & $100,00 \%$ \\
\hline Positive & TEST PAP & PCR High - Inter. \\
\hline Negative & $100,00 \%$ & $93,00 \%$ \\
\hline
\end{tabular}

Table 2: (1) Comparison between HPV-Oncotect and PCR high intermediate risk in positive PAP test samples. (2) Comparison between PAP test and PCR high intermediate risk in negative HPV-Oncotect samples. (3) Comparison between PAP test and PCR high intermediate risk in positive HPV-Oncotect samples.

\begin{tabular}{|c|c|c|}
\hline Cytology Diagnosis & High Levels E6 and E7 (\%) & Type \\
\hline HSIL & 3.7 & cp8304 \\
\hline HSIL & 3.9 & 31 \\
\hline LSIL & 0.8 & Negative \\
\hline HSIL & 9.1 & 16 \\
\hline HSIL & 8.7 & 59 \\
\hline HSIL & 6 & 51 \\
\hline LSIL & 0.2 & Negative \\
\hline HSIL & 7.8 & 16 \\
\hline HSIL & 4.8 & 31 \\
\hline LSIL & 0.5 & Negative \\
\hline HSIL & 8.4 & 31 \\
\hline HSIL & 10.3 & 53 \\
\hline HSIL & 6.9 & 31 \\
\hline HSIL & 2.7 & 59 \\
\hline LSIL & 0.5 & Negative \\
\hline LSIL & 1.6 & Negative \\
\hline HSIL & 23.4 & 66 \\
\hline HSIL & 25.3 & 33 \\
\hline HSIL & 20.6 & $66 b$ \\
\hline
\end{tabular}

Table 3: Cytological diagnosis and HPV types in high levels of E6 and E7.

The cell based quantification of E6/E7 mRNA, regardless of HPV subtype, with the usage of INCELLDX HPV ONCOTECT kit is an important marker with high sensitivity $(>92 \%)$, specificity $(>85 \%)$ and PPV ( $>87 \%$ ), as compared with HR HPV PCR based techniques (Tables 1,2). Flow cytometry proved to be more efficient as a screening method, since all high risk type's samples were detected and all cell populations were well represented by flow cytometry (Figure 1A and 1B).

\section{Discussion}

In this study a total of 100 women were in parallel investigated for the adequacy of the smear/pap test by PCR and flow cytometry analysis for the detection of HPV. We report the use of flow cytometry as a rapid and more precise method in the detection of the HPV virus in comparison with PCR analysis.HPV analysis by flow cytometry is an in situ test for the detection of HPV E6 and E7 mRNA in intact ectocervical cells. It takes advantage of the fact that those oncogenic genotypes of HPV over express E6 and E7 mRNA following integration of HPV into genomic DNA.

Current investigations suggest that in situ detection of active viral mRNA precedes or coincides with morphologic changes in cervical cells signifying cervical cancer [10].

This method could identifies persistent HPV infections that can 
Citation: Kalodimou VE, Kontogiorgi M, Ghiatas A, Papalois A (2015) Human Papillomavirus: Flow Cytometry Detection and PCR Analysis, A Comparison Study. J Clin Med Genom 3: 128. doi: 10.4172/2472-128X.1000128

[Ungated] FS Log/SS Log - ADC

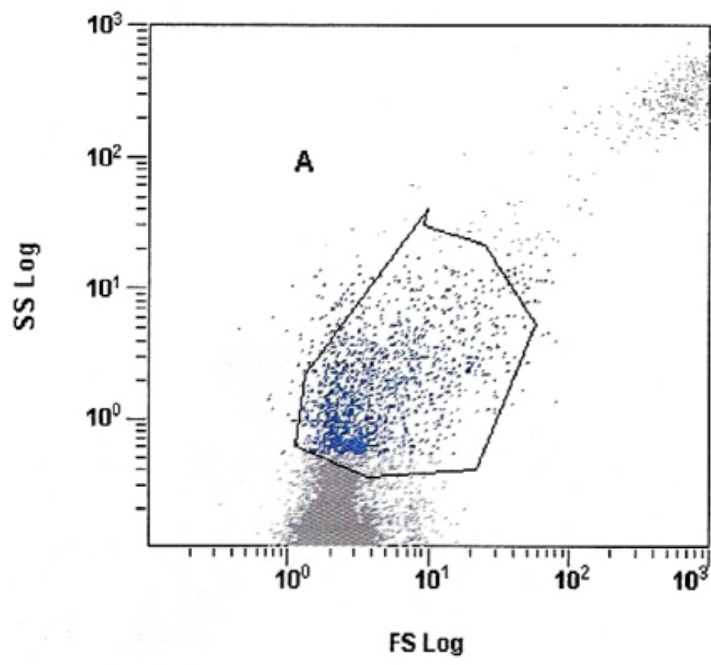

[Ungated] FS Log/SS Log - ADC

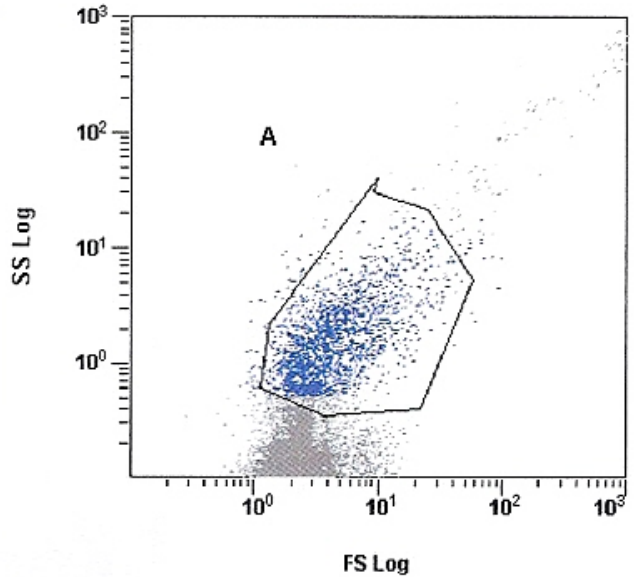

[C] FL1 Log - ADC
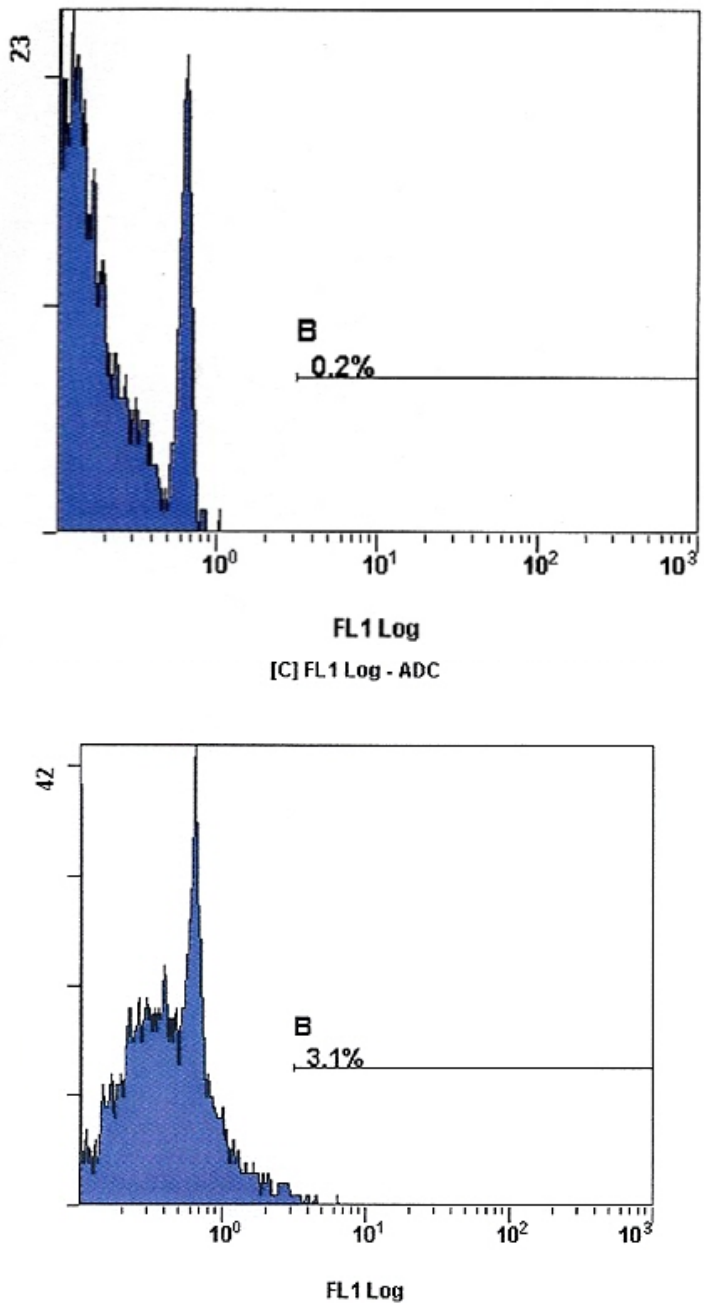

Figure 1: Flow cytometric analysis in cytomics FC500: A: negative sample (0.2\%) for HPV infection, B: positive sample (3.1\%) for HPV infection by flow cytometry.

progress to high-grade lesions, detects the HPV oncogenic activity analyzing cervical cells that over express oncoproteins E6 and E7, and can be used at any time of woman life because there is no low age limit, and also exclude the false negative or unsatisfactory results $[11,12]$. The specificity and positive predictive value are also higher than other HPV detection techniques such as PCR analysis. Is a rapid and precise technique and can give us a rapid quantification of the sample and because of the accuracy of the test the procedure is optimized and could lead to a lower health cost for the patient in comparison to PCR analysis which is more time consuming technique and more expensive.

Also, the importance of this analysis by flow cytometry is the estimation of sample adequacy which could be a useful indicator for the sample in consequent analysis. As a conclusion, our results showed that the use of flow cytometry in the detection of HPV virus is a feasible method and requires only $1 \mathrm{ml}$ of sample specimen to give accurate results for the diagnosis. This might be very useful in screening young women, a cohort in which the prevalence of HPV DNA positivity may be as high as $20 \%$.

\section{References}

1. Parkin DM (2006) The global health burden of infection-associated cancers in the year 2002. Int J Cancer 118: 3030-3044

2. D'Souza G, Kreimer AR, Viscidi R, Pawlita M, Fakhry C, et al. (2007) Casecontrol study of human papillomavirus and oropharyngeal cancer. $\mathrm{N}$ Engl $\mathrm{J}$ Med 356: 1944-1956.

3. Munoz N, Bosch FX, Castellsague X (2004) Against which human papillomavirus types shall we vaccinate and screen? The international perspective. International Journal of Cancer 111: 278-285.

4. Schiffman M, Castle PE, Jeronimo J, Rodriguez AC, Wacholder S (2007) Human papillomavirus and cervical cancer. Lancet 370: 890-907.

5. Schiffman M, Castle PE (2003) Human papillomavirus: Epidemiology and public health. Arch Pathol Lab Med 127: 930-934.

6. Walboomers JM, Jacobs MV, Manos MM, Bosch FX, Kummer JA, et al. (1999) Human papillomavirus is a necessary cause of invasive cervical cancer worldwide. J Pathol 189: 12-19.

7. Kahn JA (2009) HPV vaccination for the prevention of cervical intraepithelial neoplasia. N Engl J Med 361: 271-278.

8. Münger K, Howley PM (2002) Human papillomavirus immortalization and transformation functions. Virus Res 89: 213-228. 
Citation: Kalodimou VE, Kontogiorgi M, Ghiatas A, Papalois A (2015) Human Papillomavirus: Flow Cytometry Detection and PCR Analysis, A Comparison Study. J Clin Med Genom 3: 128. doi: 10.4172/2472-128X.1000128

Page 4 of 4

9. Greenblatt RJ (2005) Human papilloma viruses: Diseases, diagnosis, and a possible vaccine. Clinical Microbiology Newsletter 27: 139-145

10. Kottaridi C, Georgoulakis J, Kassanos D, Pappas A, Spathis A, et al. (2010) Use of flow cytometry as a quality control device for liquid-based cervical cytology specimens. Cytometry B Clin Cytom 78: 37-40.
11. Grundhoefer D, Patterson BK (2001) Determination of liquid-based cervical cytology specimen adequacy using cellular light scatter and flow cytometry. Cytometry 46: 340-344.

12. Narimatsu R, Patterson BK (2005) High-throughput cervical cancer screening using intracellular human papillomavirus E6 and E7 mRNA quantification by flow cytometry. Am J Clin Pathol 123: 716-723. 